\title{
Function Evaluation of Common and Proposed Friction Shock Absorbers for Open Box Wagon 12-7019 KRVZ
}

\author{
Olga Potapenko ${ }^{1}$, Nikolay Gorbunov ${ }^{1}$, Valentin Mogyla ${ }^{1}$, Yuriy Shcherbina ${ }^{2}$, Vladimir Hauser ${ }^{3}$ \\ ${ }^{1}$ Department of railway and road transport, lift and care systems, Volodymyr Dahl East Ukrainian National University. \\ 59a Tsentralny Prospect, Severodonetsk, 93406. Ukraine. E-mail: olga.alex.potapenko@gmail.com, gorbu- \\ nov0255@gmail.com, vimogila1@ukr.net. \\ ${ }^{2}$ Department of Wagons and wagon facilities, State University of Infrastructure and Technology. 19 Ivan Ogienko Street, \\ Kiev, 02000. Ukraine. E-mail: scherbina1520mm@gmail.com \\ ${ }^{3}$ Department of Transport and Handling machines, Faculty of Mechanical Engineering, University of Zilina. Univerzitna \\ 1, 01026 Zilina. Slovak Republic. E-mail: vladimir.hauser@fstroj.uniza.sk.
}

This paper deals with the research of common and the proposed wedge type shock absorbers for bogie used by 12 7019 KRVZ open box type cargo wagon. Results of elements stress-deformation state caused by static load analysis performed by computer simulation are presented. Diagram of elements displacements, spring group compression dependence on vertical load, equivalent stresses of suspension system elements, proportional load distribution diagram and diagram of energy absorption by friction damper were obtained. The influence of spring group construction to the cargo wagon dynamics when running at speeds up 10 to $200 \mathrm{~km} / \mathrm{h}$ was investigated. Advisability of the proposed wedge type shock absorbers construction improvements was confirmed.

Keywords: Wedge-Type Shock Absorber Construction, Disc Spring, Suspension System Deflection, Energy Absorption by Friction Damper, Dynamic Parameters.

\section{Introduction}

Success of high-speed transportation management depends on the technical specifications of the rolling stock, which is largely determined by construction schemes and parameters of the bogies [1]. The main and urgent objectives are improvement of the outdated rolling stock and creation of a new rolling stock that meets modern requirements for performance and reliability parameters [5]. Computational simulations are now an integral part of the development process of rolling stock. They allow a more detailed analysis of the behaviour of the vehicle as a whole or its individual parts [2]. Improving cargo wagons construction, especially wagons with increased axle load, improving their dynamic parameters, damping and absorbing systems, reducing the force impact on the elements of the track structure is one of the most important issues that is constantly being researched [7]. A promising way to create running gear for freight cars of the new generation is to create multifunctional load-bearing elastic-dissipative modules providing improved technical and economic indicators [3].

Current cargo wagon bogies spring suspension systems do not meet modern requirements of operation and, even more promising, make it impossible to increase the train speed [6]. Theoretical analysis of the research problem, as well as operating experience, has showed that one of the conditions limiting increase in the running speed and improvement of dynamic parameters of the vehicle's spring suspension and, first of all, wedge-type friction dampers are power frictional bonds of the rail vehicle bogies providing speed performance of the rolling stock [7].

The solution of this problem directly affects the technical and economic performance of the rail transport and determines its competitiveness in the transport market [10]. Literature sources and patent documentation analy- sis, as well as the developed classification of friction wedges construction features made it possible to determine the directions in the wedge-type shock absorber construction changes and the choice of parameters for the cargo wagon bogie spring suspension aimed at improving the friction wedge working area construction and using the improved spring system.

\section{Research aims and objectives}

Aim of the performed research focused to improved wedge-type friction damper for cargo wagon is determination of stress and deformation states when the static load is acting (empty and loaded state) by computer modelling; search of rational suspension characteristics taking into account the construction modifications.

Tasks of the research are spring group stiffness characteristics definition, individual load distribution to suspension elements and their stress and deformation state determination, as well as energy consumption by friction damper and dynamic behaviour evaluating after applying construction changes.

\section{Research materials and methods of the impro- ved cargo wagon friction shock absorber function}

\subsection{Research objects and software}

The research object is the elastic-friction shock absorber suspension of 18-100 cargo wagon bogie analogue model. Taking into account the geometric dimensions in accordance with the improvement project (Fig. 1), a spring suspension computer model has been developed using SolidWorks software and hardware (Dassault Systèmes) [11]. According to the completed improvement project, the elastic-friction shock absorber has a number of specific construction features, where 1 is a wedge, 2 is an external pressure spring, 3 is an internal pressure 
spring, 4 is a metal ring gasket, 5 is a disc spring. So, unlike the "common" version [14, pp. 167 - 168, fig. VII.27], the improved suspension consists of shortened external pressure spring 2 supported by metal washer 4 on disc springs group 5. The working surface of the friction wedge has a hemispherical shape that allows perceiving the load from the top of the bogie and distributing it over the improved contact plane.

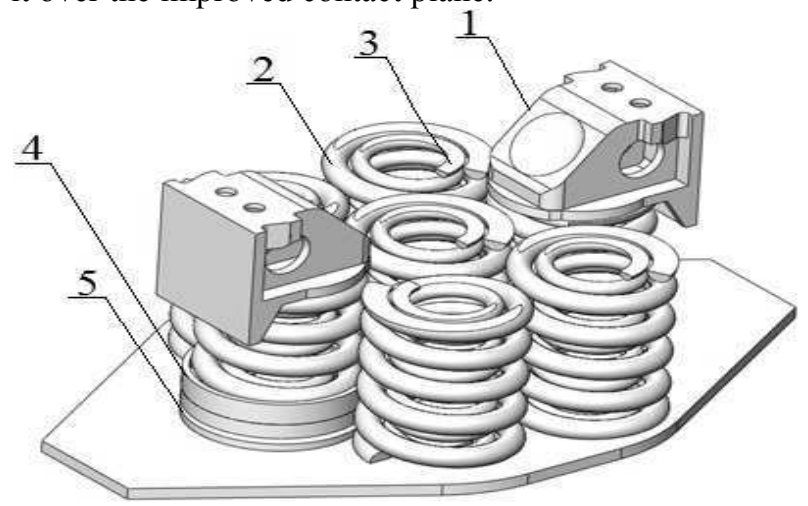

Fig. 1 Spring suspension model according to the improvement project

Research of suspension elements stress-deformation state of the cargo wagon bogie spring-friction shock absorber has also been carried out in the SolidWorks environment.

\subsection{Technique for stress state determining}

Evaluation of the critical construction elements strength involves usage of modern methods for determining the stress state, among which the most common one is the finite element method (hereinafter - FEM).

Calculation of the individual suspension elements stress-deformation state is reduced to determining the nodes displacement in the created model grid. To obtain the solution, the global stiffness matrix of finite elements is supplemented by boundary conditions that ensure immobility of the finite element model in space and prevent the stiffness matrix degeneration due to insufficient number of bonds. A prerequisite for determining the suspension elements parameters is availability of initial data: the researched construction elements geometry, the construction material mechanical characteristics; information about the existing loads and conditions for securing the individual points of the researched element.

To model the construction behavior, the state equation

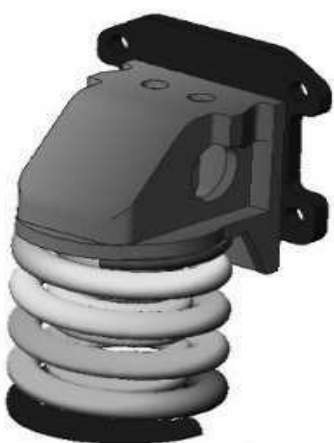

$a$

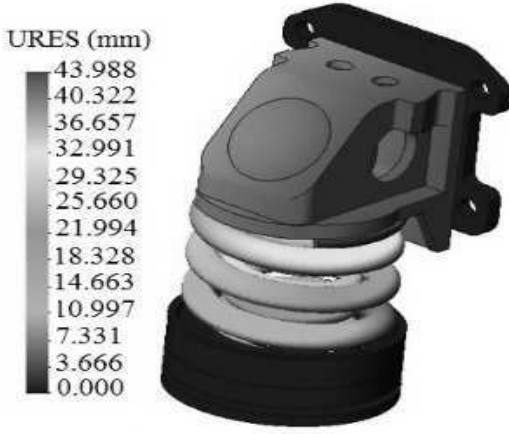

$b$ can be written in the following form:

$$
C(x) \cdot F=U
$$

Where:

$C(x)$ - the global stiffness matrix of the construction finite elements;

$F$ - the dimensionality vector of $\mathrm{n}$ state variables;

$U_{-}$the reduced loads vector at the finite element model nodes.

The restrictions are as follows:

$$
\left\{\begin{array}{l}
\xi_{i}(x, F)=\frac{\left[g_{i}\right]}{g_{i} \cdot(x, F)}-1 \geq 0, \mathrm{i}=1, \mathrm{j}_{1} \\
a_{i}<x_{i}<b_{i}, \mathrm{i}=1, \mathrm{j}_{2}
\end{array}\right.
$$

Where:

$\left[g_{i}\right], \xi_{i}(x, F)$ - respectively, standard and actual values of the state parameters in the $i$-th element of the suspension construction (stress, deflection, deformation);

$a_{i}, b_{i}$ - restrictions on the research node parameters values;

$\mathrm{j}_{1}, \mathrm{j}_{2}$ - restrictions on the state parameters and the object size.

The procedure for determining the stress state according to the FEM provides creation of a prototype computer model, setting the research preliminary boundary conditions, grid generation on a solid body with the help of the FEM, elastic suspension elements sequential study under the vertical load, depending on the wagon load ("empty" and "loaded" states). According to this technique, under the established load conditions, for the common and the proposed cargo wagon bogie spring suspension system, the initial parameters are determined, namely stress, deformation, displacement of its elements.

\section{Research results}

While carrying out the research of the stress-deformation state of the spring-friction shock absorber suspension of the cargo wagon bogie common spring suspension system, it is determined that when the vertical load that corresponds to the "loaded" state is applied, the standard system displacement equals to $\Delta_{s t}=43.99[\mathrm{~mm}]$, the proposed system displacement is $\Delta_{m}=32.8[\mathrm{~mm}]$, the proposed system displacement with the "common" wedge equals to $\Delta_{m+s t}=36.4[\mathrm{~mm}]$ (Fig. 2).
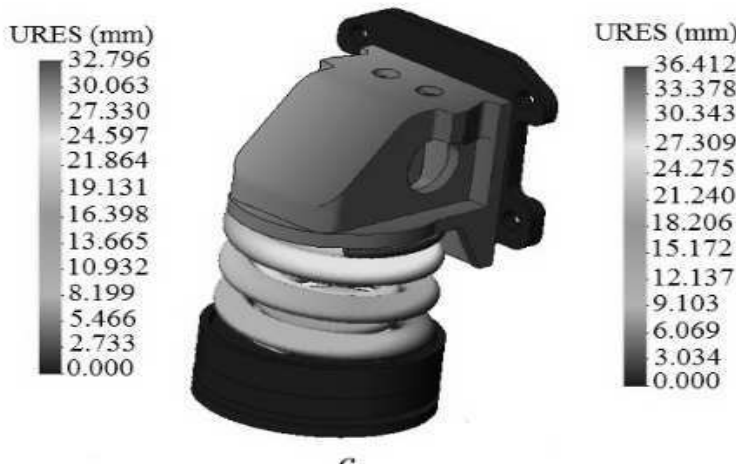

C

Fig. 2 Diagram of the spring system displacement, $a$ - a common system; $b$ - the proposed one; $c$ - the proposed one with the standard wedge 
The maximum vertical load according to [15] and [8] which is transferred from the top of the wagon to the bogies spring system is determined by the formula:

$$
P_{\text {vert } \max }=P_{s t} \cdot\left(1+K_{d}\right),[t]
$$

Where:

$P_{s t}$ - the static load acting upon the spring systems;

$K_{d}$ - the vertical dynamics coefficient, $K_{d}=0.388$ [8].

The static load is calculated in accordance with the technical specifications of 12-7019 open box cargo wagon is $P_{s t 12-7019}=85.66[t]$ in the "loaded" state, then the vertical load will be:

$$
P_{\text {vert } \text { max }}^{\text {loax }}=85.66 \cdot(1+0.388)=118.9[t] \text {. }
$$

The vertical load acting upon one system is determined by the formula:

$$
P_{\text {vert } \max 1}^{\text {loaded }}=\frac{P_{\text {vert } \text { max }}^{\text {loaded }}}{k},[t]
$$

Where:

$k$ - the number of the open box cargo wagon spring systems.

$P_{\text {vert } \max 1}^{\text {loaded }}=\frac{118.9}{28}=4.246[t]$.

For the "empty" state, the vertical load, which is transferred to one system, is $P_{\text {vert } \text { max } 1}^{\text {empty }}=0.8464[t]$. In this mode, the displacement value of the standard spring system is $\Delta_{s t}=8.77[\mathrm{~mm}]$, displacement of the improved spring system is $\Delta_{m}=6.55[\mathrm{~mm}]$, displacement of the improved spring system with the "common" wedge is $\Delta_{m+s t}=7.28[\mathrm{~mm}]$. Equivalent stresses that occur in the suspension spring system are given in Table 1.

Tab. 1 Equivalent stresses that occur in the suspension spring system

\begin{tabular}{|c|c|c|c|}
\hline $\begin{array}{c}\text { Common system, } \\
\mathrm{MPa}\end{array}$ & $\begin{array}{c}\text { Improved system, } \\
\mathrm{MPa}\end{array}$ & $\begin{array}{c}\text { Improved with the common wedge, } \\
\mathrm{MPa}\end{array}$ & $\begin{array}{c}\text { Permissible stress } \\
\sigma_{m}, \\
\mathrm{MPa}\end{array}$ \\
\hline \multicolumn{2}{|c|}{ Empty state } & \multirow{2}{*}{750} \\
\hline 81.2 & 58.7 & 60.1 & \\
\hline \multicolumn{2}{|c|}{ Loaded state } \\
\hline
\end{tabular}

The prerequisite for calculating the research object spring characteristics is availability of the initial data technical specifications of the twisted cylindrical springs of the improved suspension and the disc spring.

Stiffness of the system elements is determined in accordance with [8] and makes up $C_{1}=300\left[\frac{\mathrm{N}}{\mathrm{mm}}\right]$ for the external spring of the common suspension construction and $C_{1}=366,35\left[\frac{\mathrm{N}}{\mathrm{mm}}\right]$ for the improved one.

Stiffness of the disc spring is calculated [4], which corresponds to value $C_{\text {tarel }}=5084,5\left[\frac{\mathrm{N}}{\mathrm{mm}}\right]$. Total stiffness of the three serially connected disc springs is determined by the formula (5):

$$
\frac{1}{C_{\text {tarel. }}}=\sum_{i=1}^{3} \frac{1}{C_{\text {tarel. }}},\left[\frac{N}{m m}\right]
$$

As a result of the calculation, we have $C_{\text {tarel } 3}=1694,83\left[\frac{\mathrm{N}}{\mathrm{mm}}\right]$.

Then, in case of connecting the external shortened twisted cylindrical spring with the disc springs group, stiffness is:

$$
C_{1 P}=\frac{C_{1} \cdot C_{\text {tarel. } 3}}{C_{1}+C_{\text {tarel. } 3}},\left[\frac{N}{\mathrm{~mm}}\right]
$$

$C_{1 P}=\frac{366.35 \cdot 1694.83}{366.35+1694.83}=301.3\left[\frac{\mathrm{N}}{\mathrm{mm}}\right]$

To determine the distribution of loads among the individual elements of the spring system, a method is suggested, according to which the relationship of forces among the elements is determined by introducing the forces redistribution coefficient. Its calculation is carried out by solving the system of equations (7):

$$
\left\{\begin{array}{l}
F=k \cdot F_{1}+F_{2} \\
F=k \cdot C_{1 P} \cdot S_{1}+C_{2} \cdot S_{2},
\end{array}\right.
$$

Where:

$F_{2}$ - the force transferred to the internal spring, [N];

$\mathrm{C}_{2}$ - the internal spring stiffness of the spring system, $[\mathrm{N} / \mathrm{mm}]$;

$S_{2}$ - spring deflection under the external load, [mm].

Distribution of forces of the spring suspension system individual elements, according to the calculation results, is shown in Fig. 3.

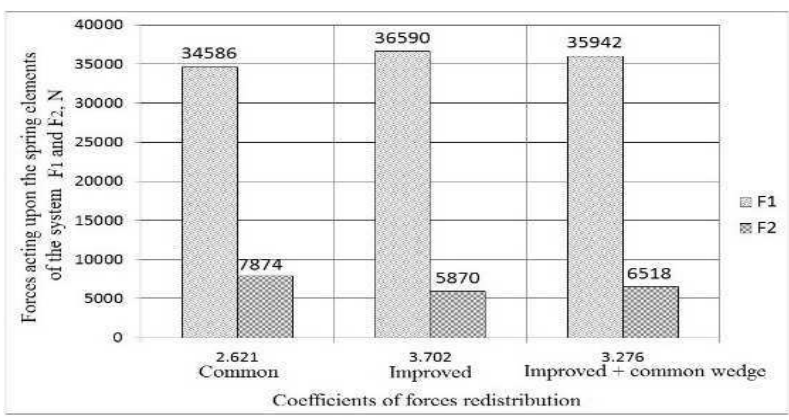

Fig. 3 Diagram of proportional load distribution in the "loaded" state

The energy that is absorbed by the friction damper under the action of the vertical load is equal to the hysteresis loop area. According to the preliminary calculation, the triangle area determines the amount of the absorbed energy on the wagon static load action under the extremely loaded state $(\mathrm{F}=42460[\mathrm{~N}])$ for various types of suspension systems (Fig. 4). 


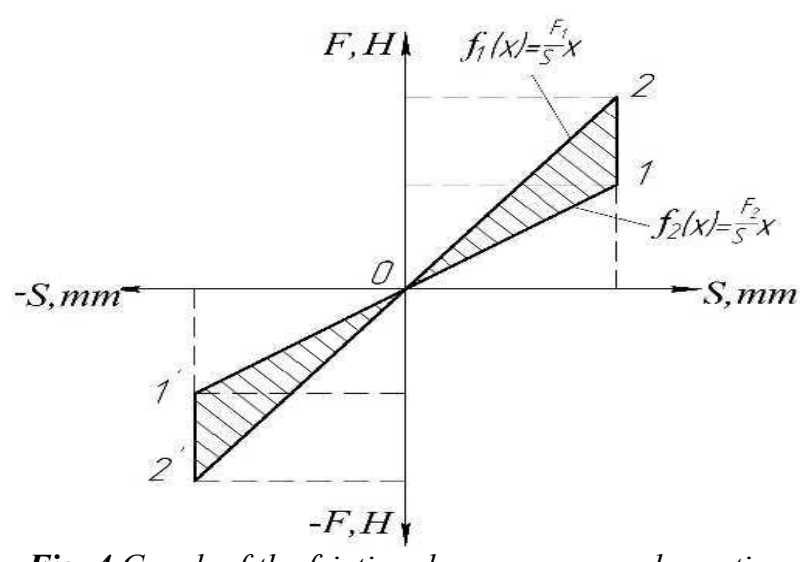

Fig. 4 Graph of the friction damper energy absorption

Analytically, energy absorption can be represented as follows [13]:

$$
S_{\text {abs.energy }}=\int_{a}^{b}\left(f_{1}(x)-f_{2}(x)\right) d x
$$

The calculation results using formula (8) are presented in Table 2.

Tab. 2 The amount of absorbed energy by the researched spring systems

\begin{tabular}{|c|c|}
\hline Suspension type & Amount of absorbed energy, J \\
\hline Common set & 588 \\
\hline Improved set & 507 \\
\hline $\begin{array}{c}\text { Improved with the } \\
\text { common wedge }\end{array}$ & 545 \\
\hline
\end{tabular}

To study the dynamic behavior of the wagon, taking into account the construction changes in the spring group in the "Universal Mechanism" software package [12], using the method of subsystems, a computer model of the wagon dynamics has been developed, the analogue of which is 12-7019 open box type wagon.

To evaluate the cargo wagon dynamics in the proposed model, the groups of output values are formed: derailment stability margin kst coefficients; frame forces acting from the bogie frame upon the wheel set; verticaldynamics coefficients; horizontal transverse and vertical accelerations of the bogie body and frames; lateral and vertical forces acting from the wheels upon the rails.

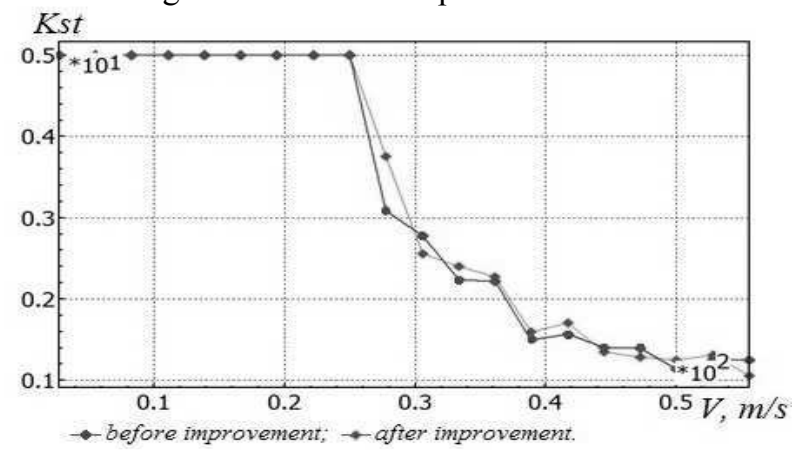

Fig. 5 The minimum values of the derailment stability margin coefficient.

Evaluation of the impact of construction changes in the spring group on the cargo wagon dynamics parameters has been carried out at speeds up 10 to $200 \mathrm{~km} / \mathrm{h}$ with pitch of $10 \mathrm{~km} / \mathrm{h}$. Modelling is performed with unworn wheel profiles and a satisfactory track condition in the "empty" state as the most unfavorable one.

The dynamic parameters analysis is performed according to the statistical estimation computed for each implementation, depending on the adopted displacement mode. The extreme values of the initial data have been determined for each calculation experiment. The obtained results of the open box cargo wagon dynamics research using computer modelling are shown in Fig. $5-8$.

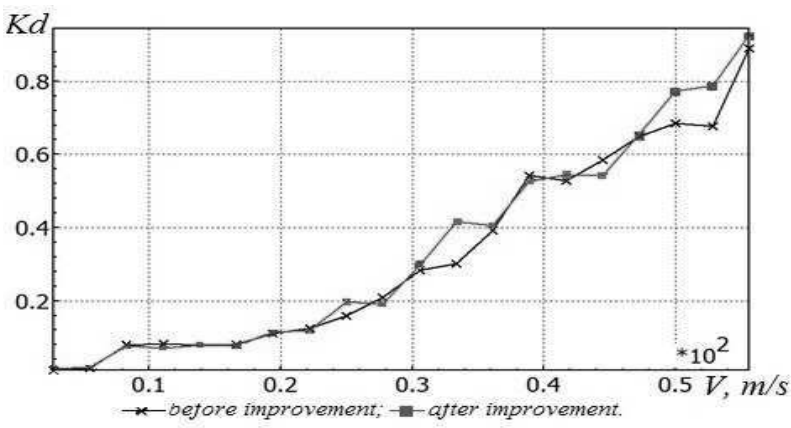

Fig. 6 The maximum values of vertical dynamics coefficients of the wagon bogie first stage suspension.

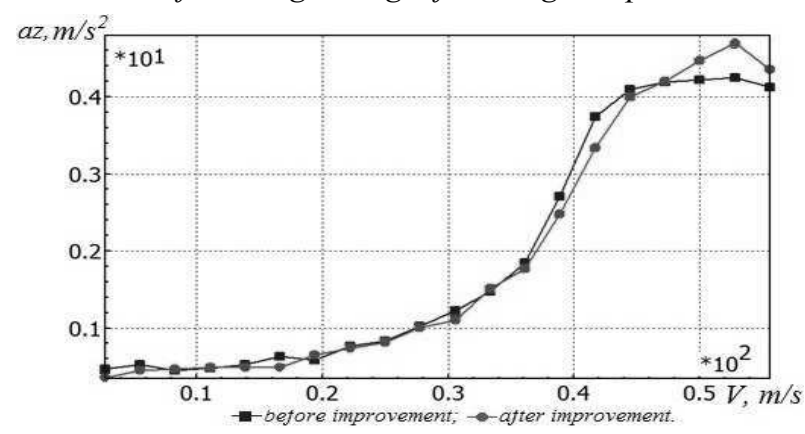

Fig. 7 The maximum values of the body vertical accelerations.

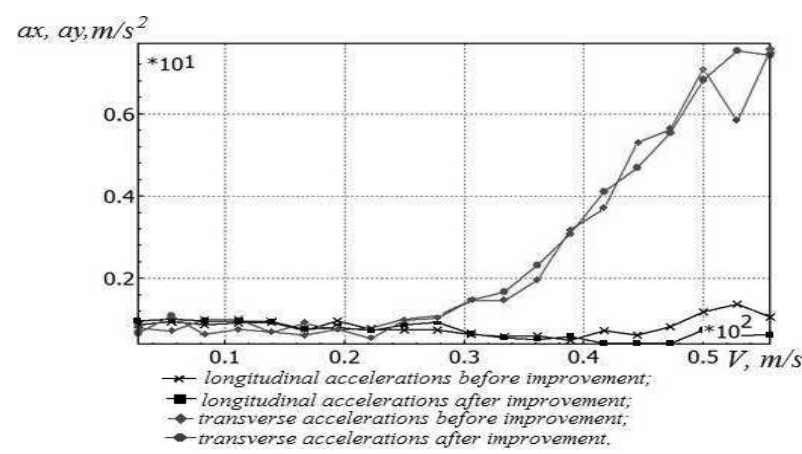

Fig. 8 The maximum values of the body horizontal accelerations.

A dangerous minimum level of the wheel sets derailment stability margin during displacement of the open box cargo wagon in the "empty" state is 1.26 , provided the wagon speed is $\mathrm{v}=150 \mathrm{~km} / \mathrm{h}$ (according to [9] $\mathrm{k}_{\mathrm{st}}>$ $1.3)$.

The obtained values of the vertical dynamics coefficients of the bogie first stage suspension of the "empty" open box cargo wagon indicate an excess of the maximum permissible margin at the speed of $\mathrm{v}=180 \mathrm{~km} / \mathrm{h}$ (according to [9] $\mathrm{k}_{\mathrm{dv} 1}<0.8$ ) and are in the range from 0.82 to 0.93 . 
The maximum values of the wagon body vertical and horizontal longitudinal accelerations are within the normative values (according to the requirements [9] $\mathrm{a}_{\mathrm{z}}=$ $0.7 \mathrm{~g}, \mathrm{a}_{\mathrm{x}}=0.3 \mathrm{~g}$ ), and horizontal transverse accelerations are $\mathrm{v}=140 \mathrm{~km} / \mathrm{h}$ (according to the requirements [9] $\mathrm{a}_{\mathrm{y}}=$ $0.3 \mathrm{~g})$.

\section{Research results}

1. Based on the results of the conducted research, it has been established that the proposed construction improvement of the cargo wagon bogie spring suspension elements leads to decrease in stresses arising in the spring-friction shock absorber under the influence of external loads by approximately $28 \%$ in the "empty" state, and by almost $12 \%$ in the "loaded" state, in comparison with the existing construction.

2. The proposed loads redistribution method for spring elements of the spring suspension allows determining forces acting upon its individual elements. At the same time, the forces redistribution coefficient is variable and allows establishing proportionality of the change in the forces among the elements, depending on the acting load.

3. The obtained power characteristics of the work, the main parameter of energy efficiency of the cargo wagon friction damper for various constructions under the extremely loaded state allowed determining the value of mechanical energy consumption in one complete cycle under the nod loading.

4. Based on the research results of the open box cargo wagon in the "empty" state by means of computer modelling, when comparing the characteristics of the "common" and the improved construction of the spring suspension system, it has been established that the given construction changes ensure a stable level of dynamic parameters within the permissible standard values up to the speed of $\mathrm{v}=140 \mathrm{~km} / \mathrm{h}$.

5. The obtained improved construction with a reduced concentration of stresses makes it possible to improve the loads transfer arising in the spring suspension, to increase the bogie dynamic characteristics, durability of the friction damper nod and to increase the lifetime between overhauls.

\section{References}

[1] CHERNIAK, H. YU., SHCHERBYNA, YU. V. (2017). Principles of building of computer model of passenger cars dynamics for high-speed movement. In: Metallurgical and Mining Industry, No.2, pp. 38 - 44. Ukrmetallurginform STA, Ltd. Dnipro, Ukraine.

[2] DIŽO, J., HARUŠINEC, J., BLATNICKÝ, M. (2018). Computation of Modal Properties of Two Types of Freight Wagon Bogie Frames Using the Finite Element Method. In: Manufacturing Technology, Vol. 18, No. 2, pp. 208 - 214. Ústí nad Labem, Czech Republic.
[3] GORBUNOV, M., GERLICI, J., KARA, S., NOZHENKO, O., CHERNYAK, G., KRAVCHENKO, K., LACK, T. New Principle Schemes of Freight Cars Bogies. In: Manufacturing Technology, Vol. 18, No. 2, pp. 233 -238. Ústí nad Labem, Czech Republic.

[4] GOST 3057 - 90. (2003). Disc Springs. General Specifications, 37 p. IPC Publishing Standards, Moscow.

[5] GUBACHEVA, L. (2010). The constructionthechnological methods to guarantee the reliability for the rolling stock of the railway. In: TEKA Commission of Motorization and Power Industry in Agriculture, V, No. XA, pp. 203 - 210. Lublin.

[6] IGEMBAYEV, N.K. (2011). Prospective Directions for Improving the Dynamic Qualities of Long-distance Cargo Wagons. In: Khabarshysy Vestnik, №3 (70), pp. 5 - 11 .

[7] MOGILA, V., POTAPENKO, O. (2016). Analysis and Study of the Problems Arising in Movable Joints of Freight Car Bogies. In: TEKA Commission of Motorization and Energetics in Agriculture, 16, No.2, pp. 27 - 32. Lublin.

[8] NORMS. (1996). Norms for Calculation and Construction of Railway Wagons of the Ministry of Railways of $1520 \mathrm{~mm}$ Gauge (Unpowered), $319 \mathrm{p}$. Gos. NIIV-VNIIZhT, Moscow.

[9] NORMS. (2001). Norms of Permissible Motion Speeds of the Rolling Stock along the Railway Tracks of 1520 (1524) mm Gauge of the Federal Railway Transport, 127 p. Transport, Moscow.

[10] NOZHENKO, O., GORBUNOV, M., MOGILA, V., PILATAU, A., CHERNIKOV, V., ANOFRIEV, A. (2011). Ways to increase the energy efficiency of locomotives. In: TEKA Commission of Motorization and Power Industry in Agriculture, 12, №4, pp. 182 - 190. Lublin.

[11] PAUL KUROWSKI. (2016). Engineering Analysis with SOLIDWORKS Simulation. $500 \mathrm{p}$.

[12] POGORELOV, D.YU. (2005). Simulation of Rail Vehicle Dynamics with Universal Mechanism Software. Rail vehicle dynamics and associated problems., pp. 13 - 58. Silesian University of Technology, Gliwice.

[13] SCHNEIDER, V.E. (1972). A Short Course of Higher Mathematics. Textbook for Higher Education Establishments, 640 p. Vysshaya Shkola, Moscow.

[14] SHADUR, L.A. (1980). Cars. Textbookfor Higher Education Establishments of Railway Transport, 439 p. Transport, Moscow.

[15] VERSHINSKY, S.V. (1971). Calculation of Wagons' Durability, 432 p. Mashinostroenie, Moscow. 